\title{
THE IMPORTANCE OF ELEMENTS OF ACTIVE LISTENING IN DIDACTIC COMMUNICATION: A STUDENT'S PERSPECTIVE
}

\author{
Flavia Mălureanu', Luiza Enachi-Vasluianu²
}

\begin{abstract}
Active listening is a core element of efficient communication, in general, and didactic communication, in particular. Proper listening improves communication, raises the level of comprehension and knowledge, and increases efficiency in everyday activities. In school, active listening is the key to sustaining the development of a student's communication competence, with direct and indirect repercussions on the quality of the learning process. Hence, it is important for students to acknowledge the indicators of efficient listening and establish their relevance in the act of didactic communication according to key criteria. Thus, our paper focuses on active listening from a students' perspective. The objectives of the research are to identify indicators of active listening, based on specific literature, and descriptively analyze the data in order to provide teachers and students with representative information concerning an efficient realization of didactic communication.
\end{abstract}

UDC Classification: 378, DOI: http://dx.doi.org/10.12955/cbup.v4.776

Keywords: communication, education, active listening, communication competence.

\section{Introduction}

Listening is a basic element of efficient communication. Even with all other communication elements at their peak (with message elaboration and transmission and avoidance of noise sources, among others), a correlation with listening is imperative for successful intercommunication. Active listening involves thinking, memorizing, and imagination that instigates reflection and emotions to analyze and evaluate. Thus, active listening has been defined as a person's willingness and ability to hear and understand. Hoppe (2006) states that, at its core, active listening is a state of mind that involves giving full and careful attention to another, by reflecting, understanding, clarifying, summarizing, and sharing information.

\section{Literature review}

An indicator of a teacher's pedagogical competence is their ability to be an effective interlocutor for students to follow with interest and manifest an active listening attitude, especially as active listening is taught and exercised like any other communication competence (Păuş, 2006). In other words, the skill of being an active listener is first learned, and later, becomes part of self-education (Agabrian, 2008). The research in our paper focuses on students' active listening. It identifies several indicators of active listening, based on specific literature and the descriptive analyses of data obtained from students participating in this study. The results provide teachers and students with representative data concerning an efficient realization of didactic communication.

Based on the literature, we propose the following set of indicators of active listening for use in continuous improvement in this fundamental dimension of efficient communication: eye contact, focus on content, receptivity to new ideas, flexibility in taking notes, listening to the whole message, paraphrasing the message, open questions, and synthetizing the message.

In any communication, eye contact may become a determinant of active listening as it suggests a positive attitude towards the interlocutor and an interest in the message. The latter may be transposed into focus on content, which implies an orientation and concentration of the cognitive activity in terms of the didactic message, as Cosmovici (1999) stated with reference to the educational context.

\footnotetext{
${ }^{1}$ Flavia Mălureanu, University of Bucharest, Faculty of Psychology and Educational Sciences, flaviamalureanu@yahoo.com ${ }^{2}$ Luiza Enachi-Vasluianu, University of Bucharest, Faculty of Psychology and Educational Sciences,

vasluianu_luiza@yahoo.com
} 
Another indicator, tightly connected to the previous one, is listening to the whole message, which demonstrates availability towards listening, the ability to follow the information transmitted, and an understanding of the information communicated. As such, one should avoid interrupting the speaker and allow them to present all ideas for one to understand their message correctly (Mălureanu \& Brebuleț, 2014).

It is generally acknowledged that students are open to new ideas, opinions, and standpoints concerning multiple educational contents. This attitude towards the new develops a student's cognitive horizon and, if properly absorbed, can become a trait of personality over time.

An apt listener takes notice using various systems. Writing allows knowledge encoding, thus enabling a certain level of systematization of the content, which is not always possible through oral communication. Negreţ-Dobridor (2005) underlines that by using various schemes, many words may be saved, and ideas better illustrated.

Paraphrasing is expressing the same content with different words or forms. Its role is to ensure the essence of the message is grasped, thus conferring with the interlocutors the certitude that they are being heard (Anghel, 2003).

In any communication, questions lead discussion on certain routes, to facilitate the discovery of new information, dispose of ambiguities and misunderstandings, or emphasize understanding. The same roles apply to didactic contexts, as questions are intended to trigger a process of information search, problem-solving, and initiate argumentative processes, among other functions. Open questions from students created and adjusted according to specific information, demonstrate the students' focus on content, and at the same time, offer relevant feedback to the teacher.

Synthetizing the message refers to summary and conclusions of any communication (Anghel, 2003). The synthesis may be represented as the scheme or main idea of educational content, either mentally or in writing.

\section{Presentation of research}

\section{Objectives}

The objectives of this research are to identify indicators of active listening, based on specific literature, and to analyze the data obtained descriptively. The purpose is to provide teachers and students with representative data to realize didactic communication efficiently.

The participants

We used a sample of 100 students from institutions majoring in pedagogical at the Pedagogical High school and Faculty of Psychology and Educational Sciences, Department for Teachers' Training, Focşani Branch, Vrancea County. The sample was split evenly in number between high school (ages 14-19 years) and faculty students (ages 19-23 years). Both groups were involved in the initial formation of a didactic career. The participation in the study was on a volunteer basis, with random sampling, which provided a variety of student appreciations.

The instrument of research

We used a questionnaire-based investigation as the main method of research. It was developed based on specific literature and focus-group discussions involving students from the two levels of schooling. As such, the series of active listening elements identified were transposed into the following variables: eye contact, focus on content, receptivity to new ideas, flexibility in taking notes, listening to the whole message, paraphrasing the message, open questions, and synthesizing the message. Each item of the questionnaire comprised a five-step scale. The respondents had the following choice in the five-step scale: (1) to a very low extent, (2) to a low extent, (3) to an average extent, (4) to a large extent, and (5) to a very large extent, when responding to questions. This procedure rated the importance of each variable in the process of active listening.

For the two sets of analyses, the t-test for the independent samples and Levene test, we used SPSS software. 


\section{Results}

Table 1: Means and standard deviation of active listening items

\begin{tabular}{|l|c|c|}
\multicolumn{1}{|c|}{ Items of active listening } & $\begin{array}{c}\text { High school } \\
\text { Mean (std. dev.) }\end{array}$ & $\begin{array}{c}\text { Faculty } \\
\text { Mean (std. dev.) }\end{array}$ \\
\hline 1. eye contact & $3.72(0.991)$ & $3.66(1.002)$ \\
\hline 2. focus on content & $4.14(0.010)$ & $4.24(0.960)$ \\
\hline 3. receptivity to new ideas & $4.02(1.185)$ & $4.08(1.010)$ \\
\hline 4. flexibility in taking notes & $3.76(1.001)$ & $3.94(0.867)$ \\
\hline 5. listening to the whole message & $4.18(0.661)$ & $4.16(1.165)$ \\
\hline 6. paraphrasing the message & $4.00(0.808)$ & $3.72(1.093)$ \\
\hline 7. open questions & $3.70(1.298)$ & $4.12(0.940)$ \\
\hline 8. synthesizing the message & $3.56(1.197)$ & $4.00(0.881)$ \\
\hline
\end{tabular}

Source: Authors

Based on the means obtained, we established a hierarchy of active listening indicators for the two school levels. As such, the indicator that ranked 1 was considered highly relevant for active listening and that which ranked 8 was less appreciated.

Table 2: Description of hierarchy of the elements of active listening

\begin{tabular}{|l|l|l|}
\hline Rank & \multicolumn{1}{|c|}{ High school } & \multicolumn{1}{c|}{ Faculty } \\
\hline 1. & listening to the whole message & focus on content \\
\hline 2. & focus on content & listening to the whole message \\
\hline 3. & paraphrasing the message & open questions \\
\hline 4. & receptivity to new ideas & receptivity to new ideas \\
\hline 5. & flexibility in taking notes & synthesizing the message \\
\hline 6. & eye contact & flexibility in taking notes \\
\hline 7. & open questions & paraphrasing the message \\
\hline 8. & synthesizing the message & eye contact \\
\hline
\end{tabular}

Source: Authors

As shown in Table 1, listening to the whole message $(\bar{X}=4.18)$ and focus on the content $(\bar{X}=4.14)$ registered the highest means for the high school students, while focus on the message $(\bar{X}=4.24)$ and listening to the whole message $(\bar{X}=4.16)$ rated highest for the faculty students. Listening to the whole message and focus on content are important to high school students because these aspects ensure the cognitive acquisitions needed to pass the graduation examination, the baccalaureate. Similarly, paraphrasing, which ranked 3 with high school students $(\bar{X}=4.00)$, facilitates the assimilation of cognitive content. In the process of active listening, at university level, the upper ranking of focus on content and listening to the whole message are explained through the student's involvement in the process of forming their own professional competences.

In general, high school responses registered means above four for focus on content $(\bar{X}=4.14)$, paraphrasing $(\overline{\mathrm{X}}=4.00)$, and receptivity to new ideas $(\overline{\mathrm{X}}=4.02)$, whereas those from faculty students 
registered means above four for listening to the whole message $(\bar{X}=4.16)$, open questions $(\bar{X}=4.12)$, receptivity to new ideas $(\bar{X}=4.08)$, and synthesizing the message $(\bar{x}=4.00)$. The results show that students consider these aspects important for efficiency of active listening. Synthesizing the message $(\overline{\mathrm{X}}=3.56)$ for high school students, and eye contact $(\overline{\mathrm{x}}=3.66)$ for faculty students, registered the lowest means.

The descriptions in Table 1 show that all means registered values above 3.50, i.e. between 3.56 and 4.18 for high school and between 3.66 and 4.24 for faculty students. This leads to the idea that active listening, through the indicators specified, is greatly important to both student groups in the research, who demonstrated that active listening is a basic element of communication competence.

For all variables analyzed, the registered means were higher for the faculty than for the high school responses. This leads to the conclusion that faculty students, who are more advanced in the initial formation of a teaching profession, understand better the importance of active listening for communication competence as a basic element in their future pedagogical activity.

There were no registered statistically significant differences for any of the items analyzed, which indicates convergence of opinions of the groups involved in the research.

\section{Conclusion}

Overall, active listening is not only imperative for the students, but also for the teacher, who must have efficient and active listening skills to motivate students to become involved in communication. Knowing how to listen is an important element of interactive feedback that avoids distortion of the message received. As such, listening must be learned systematically, as it favors effective communication and relationships.

The participants in our research had a dual role: students and teachers of the future. Their effort to learn active listening skills is an indicator of communication competence, implicitly of that related to pedagogical competence. Hence, we consider it necessary for students to know and establish the relevance of the indicators of active listening in didactic communication, according to their own criteria, as present students and future teachers. Our study may be continued with investigation of teachers' opinions on active listening to provide a different perspective, sustained by a vast experience in didactic activity. Furthermore, this research could be advanced with a comparative analysis of the opinions of students and teachers.

\section{References}

Agabrian, M. (2008). Strategii de comunicare eficientă [Effective communication strategies]. Iași: Institutul European, 166.

Anghel, P. (2003). Stiluri şi metode de comunicare [Styles and methods of communication]. Bucureşti: Aramis, 133.

Cosmovici, A., \& Iacob., L. (1999). Psihologie şcolară [School psychology]. Iaşi: Polirom.

Hoppe, M. H. (2006). Active Listening: Improve Your Ability to Listen and Lead. Greensboro: Center for Creative Leadership.

Mălureanu, F., \& Brebuleț, S. (2014). Disfuncții ale comunicării educaționale [Dysfunctions of educational communication]. Focşani: Terra.

Negreţ-Dobridor, I. (2005). Didactica nova [The new didactic]. Bucureşti: Aramis, 319.

Păuş, V. A. (2006). Comunicare şi resurse umane [Communication and human resources]. Iaşi: Polirom, 108. 